\title{
Evaluation of Emerging Antimicrobials Resistance in Nosocomial Infections Caused by E. Coli: the Comparison Results of Observed Cases and Compartmental Model
}

\author{
Mahshid Nasehi \\ IUMS: Iran University of Medical Sciences \\ Babak Eshrati \\ IUMS: Iran University of Medical Sciences \\ Hamid Reza Baradaran \\ IUMS: Iran University of Medical Sciences \\ Leila Janani \\ IUMS: Iran University of Medical Sciences \\ Sasan Ghorbani Kalkhajeh \\ Abadan University of Medical Sciences \\ Mohammad Kogani ( $\square$ mohamadkogani@yahoo.com ) \\ Abadan University of Medical Sciences
}

\section{Research}

Keywords: Antimicrobials Resistance, Emerging Antimicrobial Resistance, E.coli, Nosocomial Infections, Compartmental Model

Posted Date: November 15th, 2021

DOI: https://doi.org/10.21203/rs.3.rs-495402/v2

License: (1) This work is licensed under a Creative Commons Attribution 4.0 International License. Read Full License 


\section{Abstract}

Background: The World Health Organization repeatedly emphasizes the spread and association of nosocomial infections with microbial resistance. In a 2014 report, the World Health Organization cited microbial resistance as a global threat. In recent years, the world has seen the rapid growth of antibiotic-resistant E. coli in most areas, which poses a serious threat to public health. A high percentage of bacteria that cause nosocomial infections have been resistant to treatment. The most common bacterial agent among these nosocomial infections is $\mathrm{E}$. coli. This bacterium is one of the main causes of nosocomial infections among hospitalized patients. One of the most important goals of the Global Antimicrobial Resistance and Use Surveillance System (GLASS) is timely identification and transmission of Emerging Antimicrobial Resistance (EAR) or outbreak of antibiotic resistance. One of the main ways to identify this "emerging" at the national or local level is to identify deviations from the expected resistance in drug compounds. As a result, if the observed cases of a drug-resistant pathogen are significantly higher than expected, it could indicate "emerging".

Purpose: This study aimed to identify and transmit EAR or outbreak of antibiotic resistance among antibiotics used in the treatment of nosocomial infections caused by E. coli. This was done by comparing the observed cases of resistant E. coli with the predicted cases of resistant E. coli, which were predicted by the compartment model.

Methods: This is a hospital-based study that used data from the nosocomial infection survelliance system to investigate observed cases of antibiotic resistance. In this study, the results of 12,954 antibiogram tests related to 57 hospitals located in 31 provinces of Iran were divided into two parts (results related to the first half of 2017 and results related to the second half of 2017). The model was developed in the second half of the year to predict expected cases. Before developeing model to predict the expected cases of resistant E. coli, the validity of the model was evaluated by implementing the model in the first half of the year. Finally, the predicted cases of resistant E. coli were compared with those observed in 2017. If the difference between the two was statistically significant, it indicated the outbreak of E.coli. This model evaluated 11 antibiotics recommended by the World Health Organization that are used to treat nosocomial infections caused by E. coli.

Results: The results of this study showed that the outbreak of E. coli resistant to ampicillin and ceftazidime occurred in 2017 in hospitals of Iran. This means that resistance to ampicillin and ceftazidime antibiotics in nosocomial infections caused by $\mathrm{E}$. coli is higher than expected and has become "emerging".

Conclusion: This study showed how the outbreak of antibiotic resistance in the country's hospitals can be investigated. Using the method of this study, we can investigate the outbreak of antibiotic-resistant E. coli in the coming years and in different substrates. The results of this study showed that the administration and use of antibiotics should be reconsidered.

\section{Introduction}

The World Health Organization (WHO) has repeatedly emphasized the association of nosocomial infections with antimicrobial resistance (AMR) and its spread, and has identified it as an important public health risk that requires specific interventions.. In 2014, the World Health Organization named AMR as a global threat in a report. In this report, the main focus is on antibioticresistant (ABR). Reasons such as increasing the use of antibiotics in recent decades, widespread misuse of antibiotics in humans and animals involved in food production, lack of new treatment options in the treatment of ABR and insufficient knowledge about the spread of this type of resistant infections, led the focus of this report on $A B R[1,2]$. ABR is commonly seen in hospitals due to the high concentration of susceptible patients and the high rate of antibiotic use [3]. The most common bacterial agent in causing these infections is Escherichia coli $[2,4,5]$.

Due to the importance of this issue, at the 68th meeting of the World Health Organization, the Action Plan of AMR was developed in 2015 [6] and launched Global Antimicrobial Resistance Surveillance System (GLASS) [7]. One of the most important goals of the GLASS program is the timely detection and transmission of Emerging Antimicrobial Resistance (EAR). One of the main ways to identify this "emerging" at the national or local level is to identify deviations from the expected

Loading [MathJax]/jax/output/CommonHTML/jax.js 
resistance in drug compounds [7]. As a result, it can be said that if the observed cases of an ABR are higher than expected, it can indicate "emerging".

In Iran, increasing microbial resistance has become a concern and a major challenge for the Iranian health system. According to the World Health Organization in the Eastern Mediterranean region, which also includes Iran, there is ample evidence of the emergence of microbial resistance in a wide geographical area. However, there is no way to identify outbreaks caused by these types of infections $[8,9]$. Therefore, timely detection and communication of emerging antimicrobial resistance to identify these outbreaks seems necessary.

In Iran, according to the GLASS program, the National Nosocomial Infections Surveillance System (NNIS) [10] has been integrated with the AMR program since 2016 and has been implemented in the country's hospitals. Therefore, considering the importance of E. coli resistant pathogens in nosocomial infections, it seemed possible and necessary to study the differences between the observed cases of this pathogen and its predicted cases to identify outbreaks. It should be noted that this was not done until the time of this study for " E. coli resistant to antibiotic".

In this survelience system, according to the GLASS program, data related to 7 classes of antibiotics for E.coli pathogen are collected: 1) Sulfonamides and Trimethoprim, 2) Fluoroquinolones, 3) Third-generation cephalosporins, 4) Fourth-generation cephalosporins, 5) Carbapenems, 6) Polymyxins and 7) Penicillins. For each of these classes of antibiotics listed above, the antibiotic agent used for Antibiotic Susceptibility Test (AST) is as follows: 1) Co-trimoxazole, 2) Ciprofloxacin or Levofloxacin, 3) Ceftriaxone or Cefotaxime and Ceftazidime, 4) Cefepime, 5) Imipenem and Meropenem, 6) Colistin and 7) Ampicillin. Therefore, the purpose of this study was to evaluate emerging antimicrobials resistance in nosocomial infections caused by $E$. coli.

\section{Method And Materials}

This study is a hospital-based study examining the EAR in nosocomial infections caused by E. coli using data related to the Nosocomial Infection Care System of Iran [10]. Patients who suffer from nosocomial infections in hospitals covered by this care system, follow-up and their characteristics such as date of hospitalization, duration of hospitalization, date of infection, type of infection, type of pathogen causing the infection, patient age, patient sex, type of anti-infection test Biogram and its result are registered in the system of this care system. In 1396, 107670 cases of nosocomial infections were registered in this system, of which 15165 cases were related to nosocomial infections caused by Escherichia coli pathogen. In this study, data related to these infections were used. The observed cases of antibiotic-resistant Escherichia coli were extracted from this data and compared with the predicted cases, which were predicted by setting up a compartment model (separately for the desired antibiotics). Thus, EAR in this pathogen was investigated.

The study population in this study were patients who had a nosocomial infection caused by E. coli in Iranian hospitals between April 1 and March 20, 2017. In this study, all patients admitted to hospitals located in the centers of 31 provinces (57 hospitals) who suffered from nosocomial infections caused by E. coli and underwent antibiogram test (a total of 12,954 antibiogram tests) were included in the study. The reason for choosing the university hospitals was their greater cooperation in performing antibiogram tests and the greater number of samples required in these hospitals. Also, public hospitals are on the same level in respect of patient admission and accept a wide range of patients in different wards.

Estimation of required parameters and validation of the model used in this study. The data related to the results of these 12,954 tests were divided into two parts for some reasons as following:

Part 1) Data related to the first half of the year, with 5,701 tests performed.

Part 2) Data related to the second half of the year, with 7,253 tests performed.

To evaluate EAR in this study, the Standardized Infection Ratio (SIR) index was used[11]. This index was calculated by dividing Loading [MathJax]/jax/output/CommonHTML/jax.js esistant E.coli by the number of expected cases. If this index is greater than one, it 
may indicate EAR. A 95\% confidence interval was created to check the significance of this index. If the $95 \%$ confidence interval included the number one, it indicated that the index was not statistically significant; otherwise, and if it did not include the number one, it indicated the statistical significance of the index. To predict the expected cases of antibiotic-resistant E. coli, a compartmental model [13] was developed for each of the 11 antibiotics. The population in this type of model is classified into sections (compartments) that actually create the structure of the model. In this study, the SIR structure has been used. In this structure, the subjects were divided into three sections called Susceptible (S), Infectious (I) and Remove (R). S denotes patients with E.coli nosocomial infections. I denotes nosocomial infections due to E.coli that developed antibiotic resistance, and $\mathrm{R}$ denotes resistant cases of E. coli that were discharged from the hospital for any reason (death, treatment). The model predicts the transfer of people between these segments with pre-determined coefficients. In this study, the probability of transferring people from section $\mathrm{S}$ to section $\mathrm{I}$, with the incidence rate (ir) and transferring people from section I to section $\mathrm{R}$, with the remove rate (rr). The "Difference Equations" approach was used to set up the model. In this approach, the transfer of items between sections is described using "Discrete time steps" (such as days). In fact, this method is to estimate the number of cases at a particular time [13]. In this study, with the help of these equations, the transition from part S to part I and from part I to part R in the time unit of the day was described. Thus, the number of new cases of antibiotic-resistant E. coli in the days in question was estimated. To set up these equations, " Euler" method was used in Berkeley Madonna software version 8.3.23. This method is specifically used to set up this type of equation [13]. We set up the models by drawing their diagrams. Thus, instead of manually typing the equations, the model was created graphically, followed by textual equations. In this study, by drawing a model diagram, the model was developed separately for each of the 11 antibiotics (Figure 1).

The equations (Difference equations) generated by the model are shown below:

$$
\begin{gathered}
S(t+d t)=S-N e w I \\
I(t+d t)=I+N e w_{-} I-N e w_{-} r \\
R(t+d t)=R+N e w_{-} r
\end{gathered}
$$

$S(t+d t)$ : Number of cases of nosocomial infections caused by E. coli at $t+1$ time

I(t+dt): Number of resistant E. coli at $\mathrm{t}+1$ time

$\mathrm{R}(\mathrm{t}+\mathrm{dt})$ : Number of resistant $\mathrm{E}$. coli removed at $\mathrm{t}+1$ time

t: times used in the model (times between start time and end time)

$\mathrm{dt}$ : Size of time in dialy units, in this study, the number one is considered.

When developing these models, several parameters were required (INIT S, INIT I, INIT R, incidence rate (ir), remove rate (rr), start time and end time. INIT S, INIT I and INIT R were known parameters, and their values were available at the beginning of the study. INIT S were all cases of E. coli nosocomial infections for which antibiogram test was performed. INIT I, the number of patients with resistant E. coli was at the beginning of the study, which is considered "1" in these models. INIT R, cases of resistant E. coli were discharged from the hospital at the beginning of the study, which are considered "zero" in these models. The rest of the parameters including ir, $\mathrm{rr}$, start time and end time were among the unknown parameters of the model, the values of which should have been determined by examining the texts. Since this study was the first study to investigate EAR in nosocomial infections caused by E. coli with the help of the compartmental model, it was not possible to extract the unknown parameters of this model by reviewing the literature. In other words, by examining the texts, there was no similar study. As a result, these parameters were estimated using data from the first half of the year. When only one "data set" is available, it can be randomly divided into two parts, the model developed in one part and its validity evaluated in the other part [14]. The model was developed in the second half of the year to predict the expected cases of resistant E. coli. The validity and performance of the model were evaluated by performing the model in the first half of the year. If necessary (difference between model predictions and reality), the model was optimized.

Loading [MathJax]/jax/output/CommonHTML/jax.js 
Then all the new cases of predicted resistant E. coli were added together. Thus, the total number of predicted cases of E. coli resistant to 11 antibiotics was estimated. In this study, cross-validation method was used to evaluate the validity of the model. In this method, before the model was implemented to investigate resistant E. coli outbreak in the second half of the year, it was first performed to evaluate its validity in the first half of the year. The output of the model implemented in the first half of the year was compared with the cases observed in the same half. In other words, the predicted cases of resistant E. coli were compared by the model with the observed cases of resistant E. coli in the first half of the year.

If the resistance cases predicted in the first half of the year were similar to the resistance cases observed in this half, and there was no significant difference, it was a sign of good performance of the model and its validity. In cases where the difference between the two was statistically significant, the incidence parameter value was changed to create the smallest distance between the number of predicted cases of resistant $\mathrm{E}$. coli and the number of observed cases of resistant $\mathrm{E}$. coli. This change was made with the help of a function called "Optimize" [13] in the Berkeley Madonna program.

This function determines the distance for the incidence rate parameter ( $50 \%$ less than the incidence rate and $50 \%$ more than the incidence rate), then using the values specified in this interval, the model performed. Output of each model closer to the observed data, was selected as the optimized incidence rate. Since in this study the available data sets were divided into two parts based on time, the validity of the model is considered as the intermediate of the internal and external validity. [14].

\section{Results}

In 2017, out of 5,554 cases of nosocomial infections caused by E. coli pathogen, at least one antibiogram test was performed for 3,961 cases. Meanwhile, we kept 3,059 patients in the normal range of the "hospitalization to event" variable in the study. Among these patients, 12,954 antibiogram tests were performed to diagnose resistance for the first half of the year and the second half of the year. The mean of "hospitalization to event" variable among these patients is $8(S D=5)$ and the median of "hospitalization to event" was 6 (range: 4-11). The mean age of those surveyed was 57 (SE=0.4). Regarding gender, $53 \%$ were men. The mean age of those surveyed in the first half of the year (first part of the data) and the second half of the year (second part of the data) was $56(\mathrm{SE}=0.6)$ and $58(\mathrm{SE}=0.5)$, respectively. Regarding gender, $57 \%$ of those surveyed in the first half of the year were male. Among those surveyed in the second half of the year, $54 \%$ were male (Table 1 ).

The results of the model implemented in the first half of the year can be seen in Table 1 to check the validity of the model. In this table, the number of expected cases that the compartment model has predicted in the first part of the data to check the validity of the model can be seen. These items are displayed in the "Expected cases" column. "Optimized model expected cases " is also displayed in the last column. In this table, the model output (expected cases) for ceftriaxone (CEF), cefotaxime (CTX) and cotrimoxazole (SXT) antibiotics were significantly different from the observed cases. By optimizing the parameter, the incidence of these two became as similar as possible. Finally, in Table 2, the optimized developed model by antibiotic can be seen.

Loading [MathJax]/jax/output/CommonHTML/jax.js 
Table 1

Incidence and optimized incidence of resistant E. coli by antibiotic

\begin{tabular}{|c|c|c|c|c|c|c|c|c|}
\hline Antibiotic & $\begin{array}{l}\text { Nosocomial } \\
\text { infections }\end{array}$ & $\begin{array}{l}\text { Observed } \\
\text { cases }\end{array}$ & $\begin{array}{l}\text { Number of } \\
\text { person-days of } \\
\text { hospitalization }\end{array}$ & $\begin{array}{l}\text { Incidence } \\
\text { rate } \\
(95 \% \mathrm{Cl})\end{array}$ & $\begin{array}{l}\text { Expected } \\
\text { cases }\end{array}$ & $\begin{array}{l}P \\
\text { value }\end{array}$ & $\begin{array}{l}\text { Optimized } \\
\text { incidence }\end{array}$ & $\begin{array}{l}\text { Optimized } \\
\text { Expected } \\
\text { cases }\end{array}$ \\
\hline $\begin{array}{l}\text { Ampicillin } \\
\text { (AMP) }\end{array}$ & 185 & 150 & 1926 & $\begin{array}{l}0.08 \\
(0.07- \\
0.09)\end{array}$ & 135 & $\mathrm{~N}^{1}$ & - & - \\
\hline $\begin{array}{l}\text { Ceftazidime ( } \\
\text { CAZ) }\end{array}$ & 381 & 247 & 3579 & $\begin{array}{l}0.07 \\
(0.06- \\
0.08)\end{array}$ & 243 & $\mathrm{~N}$ & - & - \\
\hline $\begin{array}{l}\text { Ceftriaxone } \\
\text { (CEF) }\end{array}$ & 498 & 381 & 4684 & $\begin{array}{l}0.08 \\
(0.07- \\
0.09)\end{array}$ & 343 & $Y^{2}$ & 0.1 & 385 \\
\hline $\begin{array}{l}\text { Cefotaxime } \\
\text { (CTX) }\end{array}$ & 364 & 294 & 3596 & $\begin{array}{l}0.08 \\
(0.07 \\
-0.09)\end{array}$ & 251 & Y & 0.1 & 281 \\
\hline $\begin{array}{l}\text { Cefepime ( } \\
\text { CFP) }\end{array}$ & 306 & 218 & 3124 & $\begin{array}{l}0.07 \\
(0.06 \\
-0.08)\end{array}$ & 203 & $\mathrm{~N}$ & - & - \\
\hline $\begin{array}{l}\text { Ciprofloxacin ( } \\
\text { CIP) }\end{array}$ & 714 & 490 & 6552 & $\begin{array}{l}0.07 \\
(0.06 \\
-0.08)\end{array}$ & 455 & $\mathrm{~N}$ & - & - \\
\hline $\begin{array}{l}\text { Levofloxacin ( } \\
\text { Lvx) }\end{array}$ & 73 & 48 & 652 & $\begin{array}{l}0.07 \\
(0.06 \\
-0.1)\end{array}$ & 48 & $\mathrm{~N}$ & - & - \\
\hline Colistin ( CST) & 87 & 13 & 934 & $\begin{array}{l}0.01 \\
(0.008- \\
0.02)\end{array}$ & 11 & $\mathrm{~N}$ & - & - \\
\hline $\begin{array}{l}\text { Imipenem } \\
\text { (IPM) }\end{array}$ & 563 & 145 & 5517 & $\begin{array}{l}0.02 \\
(0.02 \\
-0.03)\end{array}$ & 147 & $\mathrm{~N}$ & - & - \\
\hline $\begin{array}{l}\text { Meropenem } \\
\text { (MEM) }\end{array}$ & 319 & 95 & 3285 & $\begin{array}{l}0.03 \\
(0.02 \\
-0.04)\end{array}$ & 114 & $\mathrm{~N}$ & - & - \\
\hline $\begin{array}{l}\text { Cotrimoxazole } \\
\text { (SXT) }\end{array}$ & 530 & 410 & 4911 & $\begin{array}{l}0.08 \\
(0.07 \\
-0.09)\end{array}$ & 351 & Y & 0.1 & 395 \\
\hline
\end{tabular}

1: Not significant

2: Significant 
Table 2

Parameters required to develop the model, by antibiotic

\begin{tabular}{|llll|}
\hline Antimicrobial agents & ir & $\boldsymbol{\pi}$ & Start time - Stop time \\
\hline Ampicillin & 0.08 & 0.1 & $4-20$ \\
\hline Ceftazidime & 0.07 & 0.09 & $4-18$ \\
\hline Ceftriaxone & 0.1 & 0.1 & $4-18$ \\
\hline Cefotaxime & 0.1 & 0.09 & $4-18$ \\
\hline Cefepime & 0.07 & 0.08 & $4-19$ \\
\hline Ciprofloxacin & 0.07 & 0.1 & $4-18$ \\
\hline Levofloxacin & 0.07 & 0.14 & $3-18$ \\
\hline Colistin & 0.01 & 0.06 & $5-18$ \\
\hline Imipenem & 0.02 & 0.08 & $4-19$ \\
\hline Meropenem & 0.03 & 0.09 & $4-19$ \\
\hline Cotrimoxazole & 0.1 & 0.11 & $4-17$ \\
\hline
\end{tabular}

b. Remove rate per day

$\mathbb{~}$ : Time period over which the model is run in daily units

Finally, we implemented the model in the second part of the data, the results of which can be seen in the Table 3. This table shows the number of nosocomial infections caused by E. coli in the second part of the data acros antibiotic. The expected number of cases of resistant E. coli predicted by the model can be seen. Finally, the SIR index is calculated for each antibiotic. 
Table 3

Calculation of SIR index by antibiotics to evaluate "emerging"

\begin{tabular}{|c|c|c|c|c|c|}
\hline Antimicrobial agents & $\begin{array}{l}\text { Nosocomial } \\
\text { infections }\end{array}$ & $\begin{array}{l}\text { Number of resistants } \\
\text { observed }\end{array}$ & $\begin{array}{l}\text { Number of cases } \\
\text { expected }\end{array}$ & SIR & $95 \% \mathrm{Cl}$ \\
\hline Ampicillin & 215 & 192 & 158 & 1.2 & $1.1-1.3$ \\
\hline Ceftazidime & 568 & 399 & 362 & 1.3 & $\begin{array}{l}1.02- \\
1.2\end{array}$ \\
\hline Ceftriaxone & 575 & 429 & 443 & 1.03 & $\begin{array}{l}0.96- \\
1.1\end{array}$ \\
\hline Cefotaxime & 525 & 417 & 405 & 1.03 & $1-1.1$ \\
\hline Cefepime & 338 & 228 & 224 & 1.01 & $\begin{array}{l}0.90- \\
1.1\end{array}$ \\
\hline Ciprofloxacin & 802 & 537 & 512 & 1.05 & $\begin{array}{l}0.98- \\
1.1\end{array}$ \\
\hline Levofloxacin & 122 & 82 & 81 & 1 & $\begin{array}{l}0.80- \\
1.2\end{array}$ \\
\hline Colistin & 151 & 31 & 18 & 1.7 & $\begin{array}{l}1.02- \\
2.9\end{array}$ \\
\hline Imipenem & 761 & 174 & 199 & 0.87 & $\begin{array}{l}0.73- \\
1.1\end{array}$ \\
\hline Meropenem & 389 & 110 & 138 & 0.8 & $\begin{array}{l}0.65- \\
0.98\end{array}$ \\
\hline Cotrimoxazole & 578 & 433 & 431 & 1 & $0.9-1.1$ \\
\hline
\end{tabular}

\section{Discussion}

There were subjects among the studied patients who had very high values from the variable "hospitalization to event". In other words, there were patients who had a long interval between their admission to the nosocomial infection. These patients, who sometimes had more than 300 days between hospitalization and nosocomial infection, could cause problems with the model if they entered the model, and greatly underestimate the incidence. At the same time, it seems that these cases are not of health or epidemiological importance in the discussion of infectious diseases. So it seemed reasonable to exclude these people from the study. To evaluate the possibility of selection bias, patients who were excluded from the study but thery were compared with other patients in respect of demographic variables (age and ender). The results of this comparison indicated a slight difference in the distribution of these variables among these patients. This finding may indicate that the selection bias in this study is unlikely.

Due to the fact that in this study, the data of a survelliance system were used, so in cases where the subjects had missing data in at least one of the variables, they were considered as non-participants. In this study, patients who were excluded from the study due to lack of information about antibiogram test were considered as non-participants. Therefore, by comparing the demographic variables of these patients with other patients, the possibility of selection bias was investigated. The results of this comparison also show a slight difference in the distribution of these variables among these patients. Therefore, it can be stated here that the probability of selection bias in this study is low. The results of this study showed that the incidence of ampicillin-resistant E. coli is significantly higher among those with nosocomial E. coli infection than expected by the model. This could mean that the incidence of ampicillin-resistant E. coli has increased significantly, which is consistent with some studies done in Turkey, Iran, and Ireland [15-17]. But it was not consistent with a study conducted in China between 2008 and 2013 [18]. A Chinese study shows that the incidence of ampicillin-resistant E. coli did not change between 2008 and 2013 . In this Chinese studv the incidence of resistance to this antibiotic was reported to be $82 \%$ between the years studied. This may Loading [MathJax]/jax/output/CommonHTML/jax.js 
be because the ampicillin-resistant E. coli outbreak in China most likely occurred before 2008 and after this year, due to less drug administration in later years and more precautions remain constant in the administration of this antibiotic.

In this study, the resistance to ceftazidime was significantly higher among patients with E. coli nosocomial infections than predicted by the model, given that this difference was also statistically significant. It can be stated that outbreak of ceftazidime resistance has also occurred among nosocomial infections caused by E. coli. The results of this section were inconsistent with a study conducted in China for the reasons described in the section on ampicillin. The incidence of ceftazidime-resistant E.a coli was reported to be $53 \%$ on average during the study period, but the trend was not increasing or decreasing between the studied years [18].

The observed cases of ceftriaxone-resistant E. coli among patients with nosocomial E. coli infection were not significantly different from those predicted by the model. These results show that during the study period, the incidence of resistance to this antibiotic did not increase or decrease significantly, which is consistent with the study conducted in China and Turkey [17, 18]. The results of this part of the study were not consistent with a study conducted in Indonesia [19]. This inconsistency can be due to reasons such as differences in study time. Given that the study in Indonesia was conducted between 1985 and 2005 , it is likely that during this time with the advent of the antibiotic ceftriaxone in the treatment of nosocomial infections and its use, E. coli resistant to this antibiotic has also increased significantly. The results of this study showed that the observed cases of cefotaxime-resistant E. coli among those with nosocomial infections caused by E. coli were not statistically significantly different from those predicted by the model. These results, like the results of the Ceftriaxone section, show that during the study period, the incidence of resistance to this antibiotic did not increase or decrease significantly. The results of this part of the study was consistent with the study conducted in China, but was not consistent with the study done in Indonesia $[18,19]$. The possible reasons for this conformity and the discrepancy are explained in the discussion on ceftriaxone.

Observations of cefipime-resistant E. coli are expected among those with nosocomial infections due to E. coli and are not significantly different from those predicted by the model. The results of this part of the study were consistent with a study conducted in China. In this Chinese study, the incidence of cefipime-resistant E. coli was reported to be $50 \%$ on average and unchanged over a 6-year period [18]. The findings of this study were not consistent with a study conducted in Turkey [17]. The findings of this study showed that the observed cases of ciprofloxacin-resistant E.coli were not significantly different from those predicted by the model. The results of this section were consistent with a study done in China, but were not consistent with a study conducted in Turkey $[17,18]$.

The observed cases of levofloxacin-resistant E. coli are the same as expected. These findings may indicate that the incidence of E. coli resistant to this antibiotic has not changed during the study period. In other words, there has been no outbreak of levofloxacin-resistant E. coli over time. This may indicate a positive effect of this antibiotic in the treatment of nosocomial infections caused by E. coli. The results of this part of the study were consistent with a study conducted in China [18]. Due to the fact that these antibiotics together with ciprofloxacin are from the class of fluoroquinolones, so it can be stated that the observed cases of E. coli resistant to fluoroquinolones in this study were as expected and the incidence of E. coli resistant to this class of antibiotics was unchanged.

The incidence of cleistine-resistant E. coli was higher among patients with E. coli nosocomial infections than predicted by the model.. These findings cannot be judged due to the low prevalence of cholecystin-resistant E. coli and the low sample size. It seems that a larger sample size is needed to examine this resistance more closely. In other words, for more detailed examination, more antibiogram tests are needed for this antibiotic. On the other hand, the high cost of this type of test has caused some hospitals to refuse to perform this test. Therefore, we can not speak with confidence about the results of this section. Observed cases of imipenem-resistant E. coli among those with nosocomial infections due to E. coli were not significantly different from those predicted by the model. In other words, in this study, for reasons such as improving health conditions and proper performance of this antibiotic against nosocomial infections, it was as expected and better than expected. Also, the incidence of meropenem-resistant E. coli was significantly lower than expected among those with Loading [MathJax]/jax/output/CommonHTML/jax.js 
nosocomial infections caused by E. coli. In other words, it can be said that the action of meropenem against nosocomial infections caused by E. coli was also appropriate.

The results of this part of the study were consistent with a study by Al-Hasan, M. N et al. [20], which showed that resistance to these antibiotics in E. coli remained low or constant over time. The results of this study were also consistent with the results of a study by Agaba, P et al. [21], showing that most antibiotic-resistant bacteria are sensitive to carbapenems. In a study by Ghadiri, $\mathrm{H}$ et al. [16], imipenem was identified as one of the most effective drugs in the treatment of nosocomial infections caused by E.coli, which was consistent with the results of this study. In general, it can be said that carbapenems show good performance in dealing with nosocomial infections caused by E. coli.

The cases of cotrimoxazole-resistant E. coli observed in all hospitals were approximately equal to those expected by the model. The results of this part of the study were consistent with a study conducted in China. In this Chinese study, the mean resistance to this antibiotic was reported to be $60 \%$ and the trend of this rate was reported unchanged during the study period [18].

This study is the first study (up to the time of performing this study) examining the outbreak of antibiotic resistance in E. coli in global level with the help of SIR index and compartment model according to GLASS. As a result, the parameters required in this study were not extracted separately in any study.

\section{Conclusion}

The results of this study showed that nosocomial infections due to E. coli resistant to fluoroquinolones, third and fourth generation cephalosporins, except ceftazidime, are expected. Cases of carbapenem-resistant $\mathrm{E}$. coli were also significantly lower than expected, which may be due to the effectiveness of these antibiotics in treating nosocomial E. coli infections. Another possible reason for the reduction in E. coli resistant to these antibiotics could be the controlled use of these antibiotics in the studied hospitals. In this study, resistance to ampicillin and ceftazidime antibiotics was higher than expected and became "emerging". Therefore, it seems that more caution should be exercised in prescribing these antibiotics. By performing AST tests in nosocomial infections caused by E. coli, before using and prescribing antibiotics in patients with nosocomial infections, their sensitivity to existing antibiotics can be checked and if they are not allergic to any of them, prescription of these antibiotics can be stopped. The results and the methods applied in this study can be used in the microbial resistance program and nosocomial infection surveillance system and strengthen this system. The results of this study can be useful and effective for health policy makers in order to take effective measures to prevent further occurrence of these resistances and overuse of antibiotics. Also, due to the changing pattern of antibiotic resistance over time, the results of this study will be helpful for clinical colleagues and specialists in this field to perform more appropriate and cost-effective treatment.

\section{Abbreviations}

GLASS: Global Antimicrobial Resistance and Use Surveillance System

EAR: Emerging Antimicrobial Resistance

WHO: World Health Organization

AMR: Antimicrobial Resistance

ABR: Antibiotic-Resistant

NNIS: National Nosocomial Infections Surveillance System

AST: Antibiotic Susceptibility Test

Loading [MathJax]/jax/output/CommonHTML/jax.js $\mathrm{X}$

Page 10/14 
SIR structure: Susceptible (S), Infectious (I) and Remove (R) structure

INIT S: initial susceptible

INIT I: initial Infectious

INIT R: initial remove

AMP: Ampicillin

CAZ: Ceftazidime

CEF: Ceftriaxone

CTX: Cefotaxime

CFP: Cefepime

CIP: Ciprofloxacin

Lvx: Levofloxacin

CST: Colistin

IPM: Imipenem

MEM: Meropenem

SXT: Cotrimoxazole

ir: incidence rate

rr: remove rate

\section{Limitations}

The microbial resistance inhibition program has been integrated into the nosocomial infection surveillance system since 2017, and this study also used data from the same year. Therefore, due to the newly established of this integration, in the mentioned data, many cases of nosocomial infections were observed, which despite being registered in the surveillance system, antibiogram testing was not performed for them. Also, the relatively high cost of antibiogram testing for antibiotics cleistine and carbapenems, compared to other antibiotics, had significantly reduced the testing of these antibiotics in 2017, which had reduced the sample size of these antibiotics.

\section{Declarations}

\section{- Ethical Approval and Consent to participate}

This study was PhD thesis in epidemiology at Iran. This study was approved by Iran University of Medical Sciences and the committee's reference number is available.

\section{- Consent for publication}

Not applicable 
All data generated or analysed during this study are included in this published article [and its supplementary information files].

\section{- Competing interests}

The authors declare that they have no competing interests - Funding

\section{- Authors' contributions}

$\mathrm{MN}$ and BE collected, recorded, analyzed and interpreted the data. HB, LJ and SGK were a major contributor in writing the manuscript. All authors read and approved the final manuscript

\section{- Acknowledgements}

Not applicable

\section{References}

1. Organization, W.H., Antimicrobial resistance: global report on surveillance. 2014: World Health Organization.

2. Von Baum, H. and R. Marre, Antimicrobial resistance of Escherichia coli and therapeutic implications. International Journal of Medical Microbiology, 2005. 295(6): p. 503-511.

3. Theuretzbacher, U., Global antibacterial resistance: The never-ending story. J Glob Antimicrob Resist, 2013. 1(2): p. 63-69.

4. WHO, Antimicrobial Resistance Global Report 2014.

5. Medina-Polo, J., et al., Prospective study analyzing risk factors and characteristics of healthcare-associated infections in a Urology ward. Investigative and Clinical Urology, 2017. 58(1): p. 61-69.

6. Global Action Plan on Antimicrobial Resistance. Available from: http://apps.who.int/gb/ebwha/pdf_files/WHA68/A68_20en.pdf?ua=1.

7. Organization, W.H., Global Antimicrobial Resistance Surveillance System: Manual for Early Implementation. Vol. 2015. 2015, Geneva, Switerland World Health Organization.

8. Moradi, G., et al., National action plan of the Islamic Republic of Iran for combating antimicrobial resistance during 20162021. Medical journal of the Islamic Republic of Iran, 2018. 32: p. 82.

9. Organization, W.H., Antimicrobial resistance global report on surveillance: 2014 summary, 2014, World Health Organization.

10. Masoumi Asl H. National Nosocomial Infections Surveillance System guidelines. 2006. Available at https://treatment.sbmu.ac.ir/uploads/0061-ofoonat.pdf

11. CDC. THE NHSN STANDARDIZED INFECTION RATIO (SIR). 2018; Available from: https://www.cdc.gov/nhsn/pdfs/psanalysis.../nhsn-sir-guide.

12. Koopman, P.A.R., Confidence Intervals for the Ratio of Two Binomial Proportions. Biometrics, 1984. 40(2): p. $513-517$.

13. E. Vynnycky and R.G. White, An Introduction to Infectious Disease Modelling. 2010, NY, New York: Oxford University Press.

14. Moons, K.G., et al., Transparent Reporting of a multivariable prediction model for Individual Prognosis or Diagnosis (TRIPOD): explanation and elaboration. Ann Intern Med, 2015. 162(1): p. W1-73.

15. Gohel, K., et al., Bacteriological profile and drug resistance patterns of blood culture isolates in a tertiary care nephrourology teaching institute. BioMed research international, 2014. 2014.

16. DGhadiri, H., et al., The antibiotic resistance profiles of bacterial strains isolated from patients with hospital-acquired bloodstream and urinary tract infections. Critical care research and practice, 2012. 2012.

17. A., S. B. and I.H. Ciftci, [Antibiotic resistance patterns of Escherichia coli strains isolated from urine cultures in Turkey: a meta-analysis]. Mikrobiyol Bul, 2013. 47(4): p. 603-18. 
18. Li, X.Y., et al., A 6-year study of complicated urinary tract infections in southern China: prevalence, antibiotic resistance, clinical and economic outcomes. Therapeutics and Clinical Risk Management, 2017. 13: p. 1479-1487.

19. Lo, W.T., et al., Changing trends in antimicrobial resistance of major bacterial pathogens, 1985-2005: A study from a medical center in northern Taiwan. Journal of Microbiology Immunology and Infection, 2011. 44(2): p. 131-138.

20. Al-Hasan, M.N., et al., Antimicrobial resistance trends of Escherichia coli bloodstream isolates: a population-based study, 1998-2007. Journal of Antimicrobial Chemotherapy, 2009. 64(1): p. 169-174.

21. Agaba, P., et al., Nosocomial bacterial infections and their antimicrobial susceptibility patterns among patients in Ugandan intensive care units: a cross sectional study. BMC Res Notes, 2017. 10(1): p. 349.

\section{Figures}

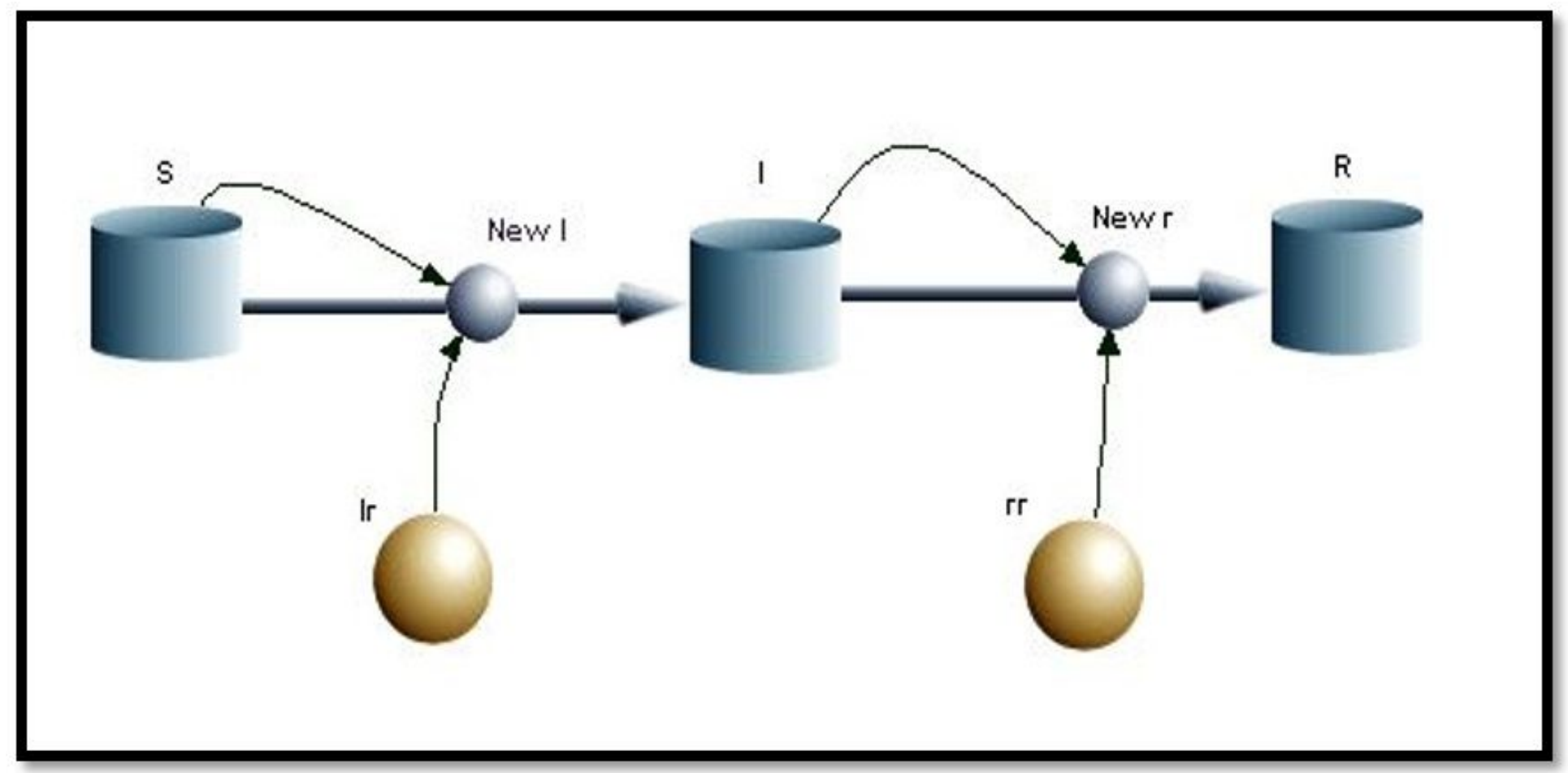

Figure 1

Diagram of developed compartment model. S: Total number of nosocomial infections caused by E. coli; ir: The incidence of resistant E.a coli per person-day hospitalization; New I: The number of cases that have become resistant between $t$ and $t+1$ time; I: Number of cases of resistant E. coli at time t; rr: The ratio of resistant E. coli discharged from the hospital per day; New $r$ : The number of cases of resistant $E$. coli that have been discharged between $t$ and $t+1$ time; $R$ : The number of cases of resistant E. coli that were discharged from the hospital at time t.

\section{Supplementary Files}

This is a list of supplementary files associated with this preprint. Click to download.

- 10MEM.dta

- 11SXT.dta

- 1AMP.dta

- 2CAZ.dta 
- 4CTX.dta

- 5CFP.dta

- 6CIP.dta

- 7LVX.dta

- 8CST.dta

- 9IPM.dta

- AMP.INDEP.SUStable.csv

- AMP.INDEP.SUS.mmd

- textprefs.txt

- total.dta

- vm.txt 